\title{
Obesity and Metabolic Programing -Does It Really Start Before Birth?
}

\author{
Joana Menezes Nunes ${ }^{1 *}$, Ana Cristina Santos ${ }^{2,3}$, José Luís Medina ${ }^{2}$ and Henrique Barros ${ }^{2,3}$ \\ ${ }^{1}$ Luz Saúde Private Hospitals, Portugal \\ ${ }^{2}$ Faculty of Medicine, University of Porto, Portugal \\ ${ }^{3}$ Institute of Public Health, University of Porto, Portugal \\ *Corresponding author: Joana Menezes Nunes, Luz Saúde Private Hospitals, Portugal \\ Submission: 制April 09, 2018; Published: 制April 13, 2018
}

Keywords: Obesity; Metabolism; Prenatal environment; Adiposity; Adipokines; Irisin

\section{Introduction}

Overweight and obesity are a growing epidemics and a major public health concern. This April2018, the Endocrine Society has just published the new Scientific Statement about obesity management [1]. One of the biggest problems society struggles with obesity is the lack of awareness for this pathology, lots of times misunderstood and misclassified with aesthetics [1]. Actually, the social stigma is still far more important than the health consequences, namely cardio-metabolic disorders (e.g. atherosclerosis, dyslipidemia, arterial hypertension, type 2 diabetes mellitus, hyperuricemia), sleep apnea and other respiratory disease, fatty liver disease, cancer and osteoarticular diseases [1-4].

Despite the lack of reimbursement by politics and health insurers [1] and the limited therapeutic options for obesity treatment, the scientific community is making an effort to better understand obesity pathways and the pharmaceutical industry is working on novel drugs [5]. Obesity appears to be determined in utero [6]. A major mechanism that is being investigated is the perturbation of the off-spring's DNA methylome, determined by both genetic and environmental influences [6-8]. Polygenic risk scores and neonatal methylation markers have been described and associated with birth weight and adiposity in early childhood [6-8].

Also, adipokines have been implicated in obesity pathogenesis. Leptin and adiponectin regulate metabolism and energy homeostasis in adults but it is still unclear their role in early life [9]. Leptin, the product of the obesity gene, informs the brain about body's energy and nutrient status [10]. It is produced by adipocytes but is also found in placenta [11]. Recent studies have been reporting that higher leptin levels in cord blood are associated with fetal adiposity at birth $[12,13]$. However, there are still conflicting results about its lifespan relationship with obesity.
Some researchers report a week association with adiposity in late childhood and adolescence [13], others found a positive association between lower cord blood leptin levels and smaller size at birth but more pronounced weight gain in the first 6 months of life and higher BMI at 3 years of age [14] and others report that higher perinatal leptin levels were associated with lower 3-year adiposity and that higher age-3 leptin levels were associated with greater weight gain and adiposity by age-7 [15]. Adiponectin is solely secreted by adipocytes, has insulin-sensitizing effects and is reduced in obese adults and inversely related to leptin leves [16]. However, there is also a grey area about its role in fatal, neonatal and childhood obesity. Some studies suggest no relation to birth weight $[12,13]$, others report a positive association with birth weight, an inverse association with weight gain in the first 6 months of life, and a positive relation with increased central adiposity at age 3 years-old [14].

On another hand, there is irisin, a myokine produced by the skeletal muscle after exercise and responsible for the 'conversion' of the white adipose tissue (an energy-saving organ) to brown adipose tissue (an energy-producing organ) [17]. New evidence suggests that irisin has a physiologic role in neonates, as irisin positively correlated with gestational age and birth weight Z-scores [18]. We believe that these conflicting results may be explained by other physiologic mechanisms of some other unknown metabolic regulators (such as irisin) and we advise that there is the need to use the same cohort from prenatal to adulthood, adjusting to environmental variables such as endocrine disruptors, to better understand the life span behavior of obesity and adiposity.

Obesity is a complex multi-factorial pathology determined in uterus and influenced by genetic, epigenetic and prenatal and 
postnatal environment factors. All these recently discovered pathways are useful in identifying individuals at higher risk and implementing preventive medical strategies to reduce obesity and metabolic diseases later in life, as well as to develop new drugs that can actually intervene since birth.

\section{References}

1. Bray GA, Heisel WE, Afshin A, Jensen MD, Dietz WH, et al. (2018) The science of obesity management: an endocrine society scientific statement. Endoc Rev 39(2): 79-132.

2. Marchesini G, Natale S, Tiraferri F, Tartaglia A, Moscatiello S, et al. (2003) The burden of obesity on everyday life: a role for osteoarticular and respiratory diseases. Diabetes Nutr Metab 16(5-6): 284-290.

3. Berger NA (2018) Young adult cancer: influence of the obesity pandemic. Obesity (Silver Spring) 26(4): 641-50.

4. Agustí A, García Pardo MP, López Almela I, Campillo I, Maes M, et al. (2018) Interplay between the gut-brain axis, obesity and cognitive function. Front Neurosci 12: 155

5. Srivastava G, Apovian C (2018) Future pharmacotherapy for obesity: new anti-obesity drugs on the horizon. Curr Obes Rep.

6. Lin X, Lim IY, Wu Y, Teh AL, Chen L, et al. (2017) Developmental pathways to adiposty begin before birth and are influenced by genotype, prenatal environment and epigenome. BMC Med 15(1): 50

7. Lillycrop KA, Burdge GC (2011) Epigenetic changes in early life and future risk of obesity. Int J Obes (Lond) 35(1): 72-83.

8. Fraser HB, Lam LL, Neumann SM, Kobor MS (2012) Populationspecificity of human DNA mathylation. Genome Biol 13(2): R8.

9. Blüher M (2009) Adipose tissue dysfunction in obesity. Exp Clin Endocrinol Diabetes 117(6): 241-250.
10.Zhang Y, Proenca R, Maffei M, Barone M, Leopold L, et al. (1994) Positional cloning of the mousse obese gene and its human homologue. Nature 372(6505): 425-432.

11. Christou H, Serdy S, Mantzoros CS (2002) Leptin in relation to growth and developmental processes in the fetus. Semin Reprod Med 20(2): 123-130.

12. Lausten Thomsen U, Christiansen M, Hedly PL, Holm JC, Schiegelow K (2016) Adipokines in umbilical cord blood from children born large for gestational age. J Pediatr Endocrinol Metab 29(1): 33-37.

13. Simpson J, Smith ADAC, Fraser A, Sattar N, Lindsay RS (2017) Programming of adiposity in childhood and adolescence: associations with birth weight and cord blood adipokines. J Clin Endocrinol Metab 102(2): 499-506

14. Mantzoros CS, Rifas Shiman SL, Williams CJ, Fargnoli JL, Kelesidis T, et al. (2009) Cord blood Leptin and adiponectin as predictors of adiposity in children at 3 years of age: a prospective cohort study. Pediatrics 123(2): 682-689.

15. Broeke CE, Mantzoros CS, Hughes MD, Rifas Shiman SL, Villamor E, et al. (2013) Differential associations of Leptin with adiposity across early childhood. Obesity (Silver Spring) 21(7): 1430-1437.

16. Hu E, Liang P, Spiegelman BM (1996) AdipoQ is a novel adipose-specific gene dysregulated in obesity. J Biol Chem 271(18): 10697-10703.

17. Bostrom P, Wu J, Jedrychowski MP, Korde A, Ye L, et al. (2012) A PGC1alpha-dependent myokine that drives brown-fat-like development of white fat and thermogenesis. Nature 481(7382): 463-468.

18. Joung KE, Park KH, Filippiaos A, Dincer F, Christou H, et al. (2015) Cord blood irisin levels are positively correlated with birth weight in newborn infants. Metabolism 64(11): 1507-1514.
Creative Commons Attribution 4.0 International License

For possible submissions Click Here

\section{Submit Article}

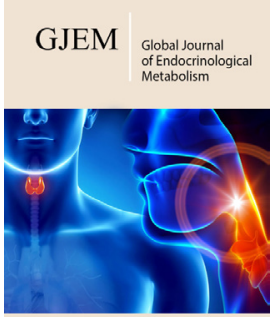

Global Journal of Endocrinological Metabolism

\section{Benefits of Publishing with us}

- High-level peer review and editorial services

- Freely accessible online immediately upon publication

- Authors retain the copyright to their work

- Licensing it under a Creative Commons license

- Visibility through different online platforms 